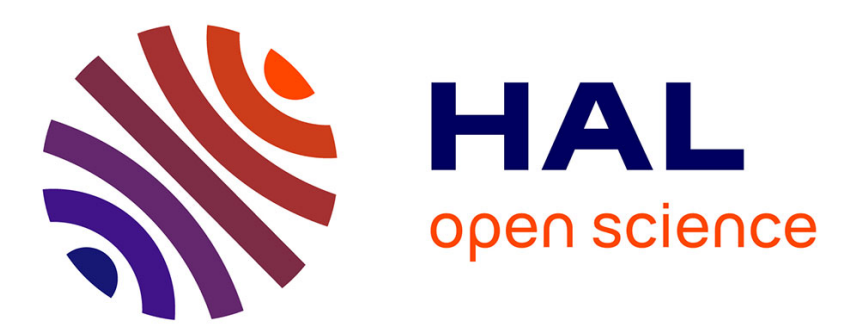

\title{
Nanoparticles of molecular conductors and superconductors: Progress over the last ten years
}

Kane Jacob, Dominique de Caro, C. Faulmann, Lydie Valade

\section{To cite this version:}

Kane Jacob, Dominique de Caro, C. Faulmann, Lydie Valade. Nanoparticles of molecular conductors and superconductors: Progress over the last ten years. European Journal of Inorganic Chemistry, 2020, 2020 (45), pp.4237-4246. 10.1002/ejic.202000761 . hal-02978164

\section{HAL Id: hal-02978164 \\ https://hal.science/hal-02978164}

Submitted on 26 Oct 2020

HAL is a multi-disciplinary open access archive for the deposit and dissemination of scientific research documents, whether they are published or not. The documents may come from teaching and research institutions in France or abroad, or from public or private research centers.
L'archive ouverte pluridisciplinaire HAL, est destinée au dépôt et à la diffusion de documents scientifiques de niveau recherche, publiés ou non, émanant des établissements d'enseignement et de recherche français ou étrangers, des laboratoires publics ou privés. 


\section{EurJIC}

European Journal of Inorganic Chemistry

\section{Chemistry Europe}

European Chemical Societies Publishing

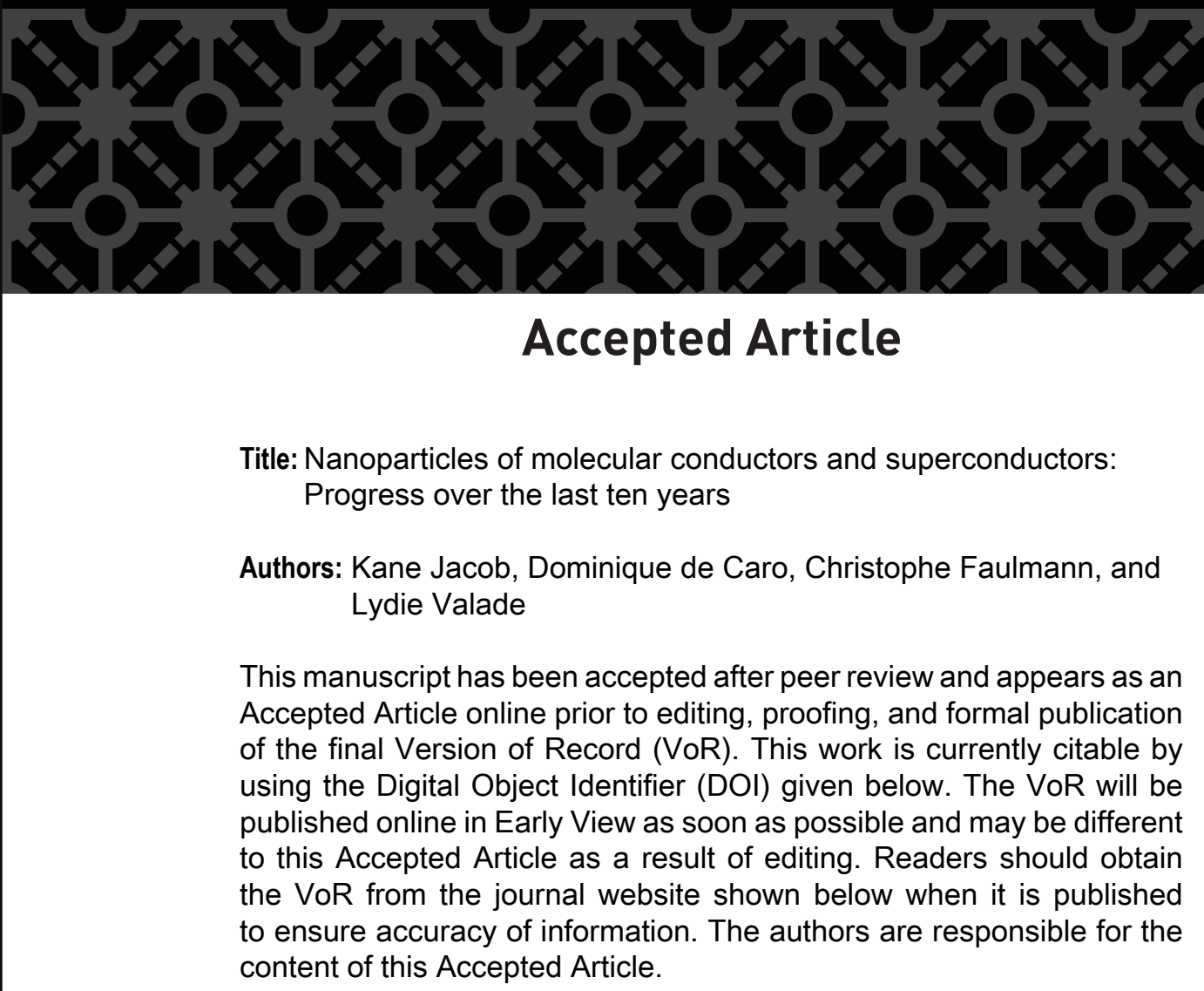

To be cited as: Eur. J. Inorg. Chem. 10.1002/ejic.202000761

Link to VoR: https://doi.org/10.1002/ejic.202000761 
WILEY-VCH

\title{
Nanoparticles of molecular conductors and superconductors: Progress over the last ten years
}

\author{
Kane Jacob, ${ }^{[a]}$ Dominique de Caro, ${ }^{[b, c]}$ Christophe Faulmann, ${ }^{[d]}$ and Lydie Valade ${ }^{\star[e]}$
}

In memory of Prof. James Brooks, Florida State University MagLab

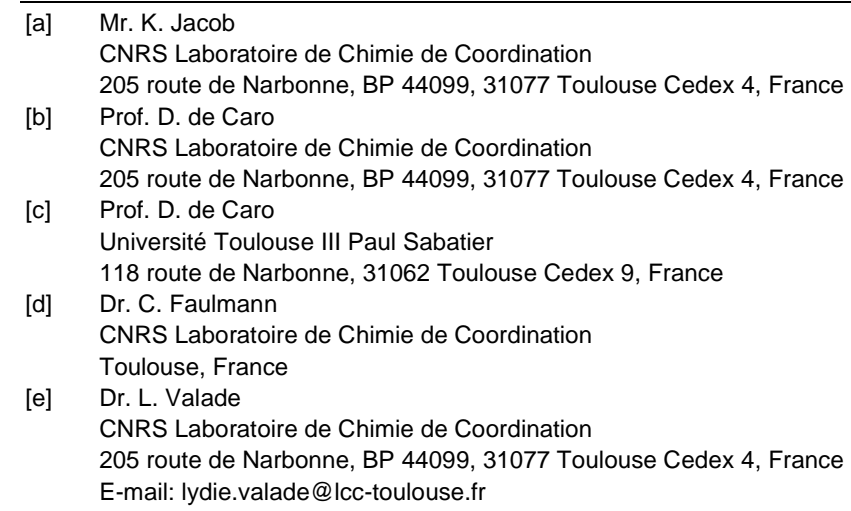

Supporting information for this article is given via a link at the end of the document.

\begin{abstract}
We review conditions for growing molecular conductors and superconductors as nanoparticles, an attractive morphology for integrating them into electronic components or composite materials. Although the one-dimensional character of these materials does not favor their growth as spheroidal objects, by adding growth controlling molecules to the reaction mixture, we succeeded in growing particles from 2 to $50 \mathrm{~nm}$ in size for fourteen systems. The choice of the growth controller depends on the nature of the chemical interactions it can establish with the reactive species to limit growth, and on the chemical or electrochemical synthesis procedure. We show that the chemical nature of the nanoparticles is alike single crystals. Due to resistive boundaries, conducting properties of nanoparticle powders are alike microcrystalline powders. Nevertheless, superconductivity occurs in three of the studied materials. The potential application of these nanomaterials is reported in four fields: composite materials, field effect transistors, thermoelectric components and biomedical materials.
\end{abstract}

\section{Introduction}

Molecule-based conductive materials appeared at the beginning of the 1970's. The more famous compound is the all-organic TTFTCNQ adduct (Figure 1) exhibiting a metallic behavior from room temperature down to $54 \mathrm{~K} \cdot{ }^{[1]}$ From this period up to the beginning of the 2000's, research in this field focused on (i) understanding the physics explaining the occurrence of metallic conductivity in these organic materials, and (ii) using other organic or metalorganic molecules in order to improve their physical properties. Rules were edited from these studies ${ }^{[2]}$ to help the choice of new building blocks (Figure 1). Superconducting phases were then identified at the beginning of the 1980's, the first examples being $(\mathrm{TMTSF})_{2} \mathrm{PF}_{6}{ }^{[3]}$ and $(\mathrm{TMTSF})_{2} \mathrm{ClO}_{4}{ }^{[4]}$ Further success came in the 1990's with the BEDT-TTF (or ET) derived compounds such as $\mathrm{ET}_{2}\left[\mathrm{Cu}(\mathrm{NCS})_{2}\right]$ which shows superconductivity above $10 \mathrm{~K} \cdot{ }^{[5]}$ Other research efforts considered the use of metalorganic building blocks. The first superconductor including a metal complex was $\operatorname{TTF}\left[\mathrm{Ni}(\mathrm{dmit})_{2}\right]_{2}{ }^{[6]}$ and the first neutral phases exhibiting metallic behavior and superconductivity were $\mathrm{Ni}(\text { tmdt })_{2}{ }^{[7]}$ and $\mathrm{Ni}(\mathrm{hfdt})_{2},{ }^{[8]}$ respectively. Numerous other systems were prepared and studied, thus increasing performance and knowledge on the conductivity mechanisms within such materials. ${ }^{[2,9]}$

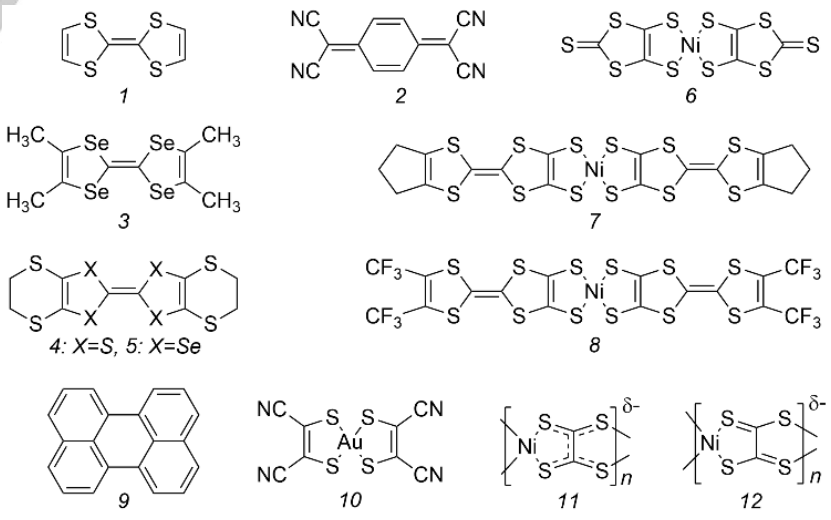

Figure 1. Molecular structures of cited building blocks.of molecular conductors. 1) tetrathiafulvalene or TTF; 2) tetracyanoquinodimethane or TCNQ; 3) tetramethyltetraselenafulvalene or TMTSF, 4) bis(ethylenedithio) tetrathiafulvalene or BEDT-TTF or ET; 5) bis(ethylenedithio) tetraselenafulvalene or BETS; 6) nickel-bis(1,3-dithiol-2-thione-4,5-dithiolate) or nickel-dimercaptoisotrithione or $\mathrm{Ni}(\mathrm{dmit})_{2}$; 7) nickelbis(trimethylenetetrathiafulvalenedithiolate) or $\mathrm{Ni}(\mathrm{tmdt})_{2} ;$ 8) nickelbis(trifluoromethyltetrathiafulvalenedithiolate) or $\mathrm{Ni}(\mathrm{hfdt})_{2}$; 9) perylene or Per; 10) gold-bis (dicyano-1,2-ethylenedithiolate) or gold-bis(maleonitriledithiolate) or $\mathrm{Au}(\mathrm{mnt})_{2}$; 11) nickel-ethylenetetrathiolate or $\mathrm{Ni}(\mathrm{ett})$; 12) nickel-tetrathiooxalate or $\mathrm{Ni}(\mathrm{tto})$. 
WILEY-VCH

During this period, molecular materials were prepared as single crystals, necessary to perform crystal structure determinations and physical measurements. As single crystals, these materials cannot be directly integrated into devices; they are insoluble and have therefore to be directly prepared either as thin films or as dispersible powders. From the beginning of the 2000's, our group investigated ways to process molecular materials on surfaces or to add them as conducting charge in composite materials. ${ }^{[10]}$ Thin films were typically grown on as received silicon substrates while microns-long nanowires were obtained on modified substrates: nano-rough oxide layers prepared either on stainless-steel or silicon surfaces, or multilamellar membranes supported on silicon. ${ }^{[1]}$ Among the various investigated systems, superconductivity was evidenced in thin films of TTF[Ni(dmit $\left.)_{2}\right]_{2}^{[12]}$ and the well-known anion-ordering occurring prior to the superconducting transition was observed in thin films of $(\mathrm{TMTSF})_{2} \mathrm{ClO}_{4}{ }^{[13]}$

Table 1. Molecular conductors and superconductors grown as nanoparticles.

\begin{tabular}{|c|c|c|c|c|}
\hline Phase $e^{[a]}$ & Family ${ }^{[b]}$ & $\begin{array}{l}\text { Growth } \\
\text { method }^{[\mathrm{c}]}\end{array}$ & $\begin{array}{l}\text { Particle size }{ }^{[d]} \\
n m\end{array}$ & References \\
\hline TTF-TCNQ & $\mathrm{CT}$ & C & 5 & [14] \\
\hline \multirow[t]{2}{*}{$\mathrm{TTF}\left[\mathrm{Ni}(\mathrm{dmit})_{2}\right]_{2}$} & CT & C & 15 & {$[14 a, 14 c, 14 e, 15]$} \\
\hline & & EC & 12 & \\
\hline $\operatorname{Per}_{2}\left[\mathrm{Au}(\mathrm{mnt})_{2}\right]$ & $\mathrm{CT}$ & EC & 20 & [16] \\
\hline TTFCl $_{0.77}$ & FC & EC & 35 & {$[14 \mathrm{e}$,} \\
\hline TTFBr $_{0.59}$ & FC & EC & 30 & {$[14 \mathrm{e}$,} \\
\hline $\mathrm{ETCl}_{0.66}$ & FC & EC & 30 & {$[14 \mathrm{e}$,} \\
\hline $\mathrm{ET}_{2} \mathrm{Br}$ & FC & EC & 25 & {$[14 \mathrm{e}$} \\
\hline $\mathrm{ET}_{2} \mathrm{l}_{3}$ & FC & C & 25 & {$[14 c, 14 g, 15 b, 19]$} \\
\hline $\mathrm{ET}_{2}\left[\mathrm{Cu}(\mathrm{NCS})_{2}\right]$ & FC & C & 28 & {$[17 \mathrm{~b}, 20]$} \\
\hline$(\mathrm{TMTSF})_{2} \mathrm{PF}_{6}$ & FC & EC & 50 & {$[14 \mathrm{e}, 15 \mathrm{~b}, 17 \mathrm{~b}, 21]$} \\
\hline$(\mathrm{TMTSF})_{2} \mathrm{ClO}_{4}$ & FC & EC & 25 & {$[14 e, 15 b, 21]$} \\
\hline$(\mathrm{BETS})_{2} \mathrm{FeCl}_{4}$ & FC & EC & 15 & This work \\
\hline $\mathrm{Ni}(\mathrm{ett})$ & $\mathrm{CP}$ & $\mathrm{C}$ & 14 & [22] \\
\hline $\mathrm{Ni}(\mathrm{tto})$ & $\mathrm{CP}$ & C & $7^{[e]}$ & [23] \\
\hline
\end{tabular}

[a] $\mathrm{ET}=\mathrm{BEDT}-\mathrm{TTF} ;[\mathrm{b}] \mathrm{CT}=$ Charge-Transfer, $\mathrm{FC}=$ Fractional oxidation state compound, $\mathrm{CP}=$ Coordination polymers; $[\mathrm{c}] \mathrm{C}=$ Chemical method, $\mathrm{EC}=$ Electrochemical method; [d] mean diameter of nanoparticles issued from reproducible syntheses giving the smallest particles with the lowest dispersion in size; [e] nanoparticles dispersed in a matrix of the same nature.
During the past ten years, we focused our research on their synthesis as nanoparticles, because this morphology allows their preparation as stable dispersions or colloidal solutions, in favor of a homogeneous integration on surfaces or within composite materials. Besides these applicative goals, fundamental studies of their properties at the nanoscale were also conducted.

We will review here the synthesis, properties and applications of the molecular conductors and superconductors that were grown as nanoparticles (Table 1).

\section{Reasons and means for growing molecular conductors as nanoparticles}

Among characteristic features encountered within molecular materials, their insolubility and low vapor pressure are barriers in terms of applications, as they forbid their further use via the solution process or vapor-phase techniques commonly used in the electronic industry. Therefore, for envisioning their integration into devices, synthetic procedures should be adapted to their direct preparation in the expected morphology. A few examples of reactive vapor-phase techniques or electrochemical deposition on surfaces have been reported for obtaining thin films of molecular materials. ${ }^{[10 a, 10 c, 24]}$ Chemical procedures using stabilizing agents that control the particles growth have widely proved to be efficient to produce colloidal solutions of metals ${ }^{[25]}$. Solution procedures towards oxide functional nanoscale materials have been reviewed ${ }^{[26]}$. However, while the 3-D structure of metals favors the formation of spheroidal particles, the largely encountered 1-D or quasi 1-D structural arrangement of molecular conductors ${ }^{[2]}$ is the driving force leading to their formation as elongated crystals. Indeed, molecular conductors grow as needles or platelets due to their intrinsic structure. For example, the structure of TTF-TCNQ consists in independent stacks of TTF and TCNQ moieties, that of $(\mathrm{TMTSF})_{2} \mathrm{ClO}_{4}$ also exhibits stacks of TMTSF molecules separated by perchlorate anions layers (Figure 2). [a]

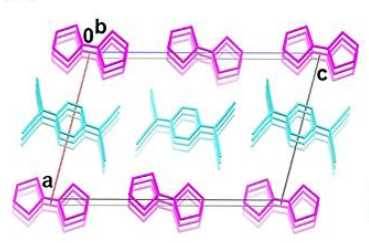

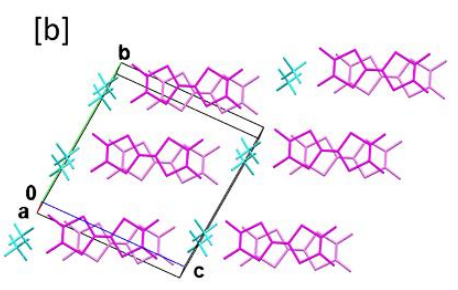

Figure 2. Typical molecular stacking within [a] the CT compound TTF-TCNQ and [b] the FC compound (TMTSF) ${ }_{2} \mathrm{ClO}_{4}$. TTF and TMTSF (magenta), TCNO and $\mathrm{ClO}_{4}^{-}$(cyan).

This arrangement at the molecular level is transposed into the morphology of crystals: the direction of elongation of needles typically fits the stacking direction. The conductive properties mainly develop along the stacking axis and may be one to three orders of magnitude lower along other directions. Efficient interstack molecular interactions may create effective conductive pathways contributing to the stabilization of metallic or superconductive states at low temperatures. The needle morphology is enhanced when the material is electrochemically grown, because crystals preferably grow along the highest conductive direction, i.e. the molecular stacking axis. It was 
WILEY-VCH

\section{MINIREVIEW}

therefore not obvious to control the growth of molecular conductors in the form of spheroidal nanoparticles. Over the past ten years, we have taken up this challenge and prepared nanoparticles of the fourteen molecular conductors and superconductors listed in Table 1. We investigated three families of conductors and superconductors (Table1): charge transfer (CT) compounds such as TTF-TCNQ, fractional oxidation state (FC) compounds such as (TMTSF) $)_{2} \mathrm{ClO}_{4}$, and coordination polymers (CP) such as Ni(tto).

The following sections will describe the synthetic conditions for growing nanoparticles of molecular conductors, their general characteristics in terms of morphology and chemical composition, their physical properties compared to the bulk materials, and the applications domains that could be investigated.

\section{Conditions for growing nanoparticles of molecular conductors}

Synthetic methods of nanoparticles of molecular conductors have been reviewed:[27] template chemistry consists in growing the material within the pores of a solid matrix ${ }^{[28]}$, embedment in a polymer results in composite materials, ${ }^{[14 c, 14 e, 18]}$ and addition of a growth controlling agent to the reaction mixture affords isolated nanoparticles. This section will focus on this third method and discuss the selection and role of the additional agents according to the applied chemical or electrochemical synthetic method.

\subsection{Characteristics and role of selected growth controlling agents}

In order to constrain the material to grow as individual small spheroidal entities during the synthesis step, we investigated the addition of three families of growth controlling agents: ionic liquids, long-chain ammonium salts, and neutral amphiphilic molecules (Table 2).

The first family is lonic liquids which are salts containing bulky non-symmetric organic cations associated with inorganic or organic anions, and being liquid at ambient temperature. They are used, for example, as solvent for organic synthesis, catalysis and electrochemical studies because they offer wide electrochemical windows. ${ }^{[29]}$ Imidazolium based ionic liquids are known to organize into nanodomains, at low temperature or in the presence of a solvent, ${ }^{[30]}$ thus defining "nanoflasks" where a crystal growth can be constrained. This property has been successfully used for growing nanoparticles of metals ${ }^{[25]}$ or Prussian Blue compounds. ${ }^{[31]}$ Both their ability to act as soft template for nanostructure control and their ionic composition are of interest for growing nanoparticles of molecular conductors using either chemical or electrochemical procedures.

The second and third families include long-chain ammonium salts, neutral amphiphilic amines, carboxylic acids or carboxylate esters, and neutral polymers. They are expected to act as surfactants around the crystal germs, through both their bulky hydrocarbon long chains and the possible ionic/covalent/ $\pi$-overlapping interactions between their terminal functional groups and the material building blocks. Indeed, colloidal solutions of metals, metal oxides and sulfides were prepared using neutral amphiphilic molecules. ${ }^{[32]}$ The solubility of these nanoparticles is explained by the coordination of the molecules to the metal center

\section{Table 2. Families and examples of growth controlling agents}

\begin{tabular}{lll}
\hline Ionic liquids & $\begin{array}{l}\text { Long-chain ammonium } \\
\text { salts }\end{array}$ & $\begin{array}{l}\text { Neutral amphiphilic } \\
\text { molecules and polymers }\end{array}$ \\
\hline$(\mathrm{BMIM}) \mathrm{X}^{[\mathrm{a}]}$ & {$\left[\left(n-\mathrm{C}_{8} \mathrm{H}_{17}\right)_{4} \mathrm{~N}\right] \mathrm{X}$} & $n$-octylamine $(n$-Oct $)$ \\
$(\mathrm{EMIM}) \mathrm{X}^{[\mathrm{b}]}$ & {$\left[\left(\mathrm{CH}_{3}\right)\left(n-\mathrm{C}_{8} \mathrm{H}_{17}\right)_{3} \mathrm{~N}\right] \mathrm{X}$} & $n$-dodecylamine \\
$(\mathrm{DMIM}) \mathrm{X}^{[\mathrm{c}]} \mathrm{n}=10$ & {$\left[\left(n-\mathrm{C}_{12} \mathrm{H}_{25}\right) \mathrm{NH}_{3}\right] \mathrm{X}$} & $n$-hexadecylamine \\
$(\mathrm{HDMIM}) \mathrm{X}^{[\mathrm{c}]} \mathrm{n}=14$ & & trans-2-decenoic acid
\end{tabular}

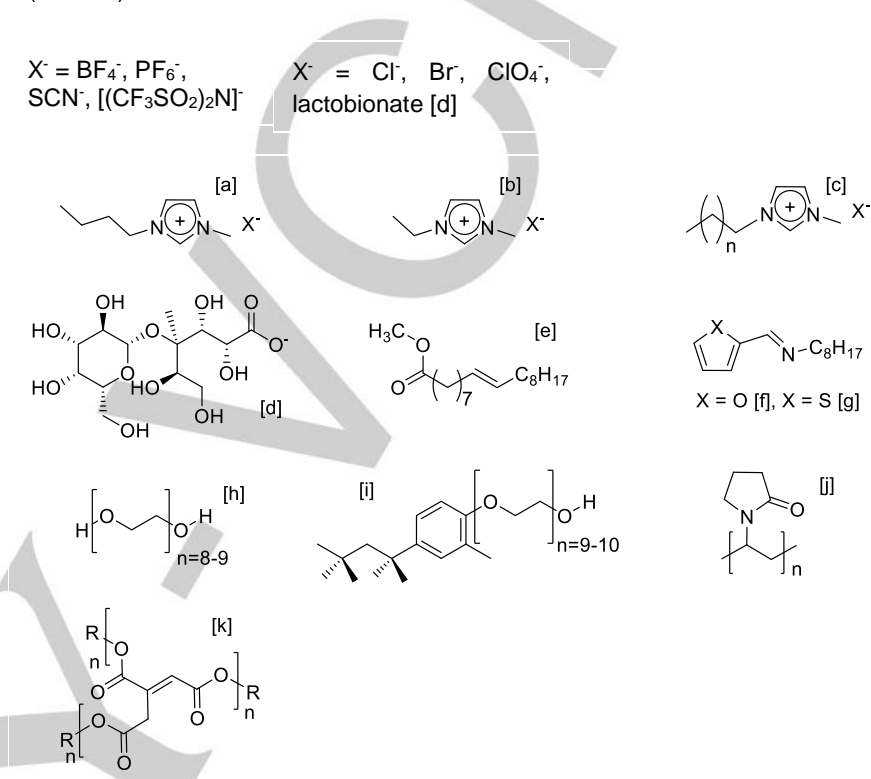

[a] (BMIM) $^{+}$: 1-butyl-3-methyl-imidazolium, [b] (EMIM)+: 1-ethyl-3-methylimidazolium, [c] (DMIM)+: $n=10,1$-dodecyl-3-methyl-imidazolium, (HDMIM)+: $\mathrm{n}=14,1$-hexadecyl-3-methyl-imidazolium, [d] lactobionate, [e] methyloleate, [f] $\mathrm{N}$-octylfurfurylimine, [g] 1-octanamine- $\mathrm{N}$-(2-thienylmethylene), [h] PEG 400: polyethyleneglycol 400, [i] Triton $X$ : polyethyleneglycol-p-(1,1,3,3tetramethylbutyl)-phenylether, [j] PVP: polyvinyl pyrrolidone, [k] hyperbranched biobased polyesters of aconitic acid with $\mathrm{R}=$ glyceryl or 1,4-butanedioxy.

Finally, the selection of growth controlling agent was performed with the aim to reduce the number of involved chemical species. At minima, the building blocks of the expected material and the growth controlling agent should be present. In the case of fractional oxidation state materials grown by electrocrystallization, the counter ions can be afforded by the imidazolium or the longchain ammonium salts. Therefore, these agents play a triple role: supporting electrolyte, source of anion of the expected material, and growth control via the cation nature.

\subsection{Chemical method}

The chemical procedure was applied to charge transfer compounds, coordination polymers, and a few fractional oxidation state compounds. Ionic liquids are chosen here for their soft template structuring ability and neutral amphiphilic molecules and polymers for their surfactant properties.

General conditions. Typically, increasing amounts of the growth controlling agent are added to the reaction mixture used for growing macroscopic crystals. In any case, in absence of growth controller, needle-like crystallites are obtained (Figure 3a), while nanoparticles form upon adding a growth controlling species 


\section{WILEY-VCH}

\section{MINIREVIEW}

(Figures $3 b, c, d)$. In order to dissolve the material precursors, a mixture of the usual reaction solvent and the growth controller is necessary to obtain a homogenous reaction medium, even with good solvents as ionic liquids. ${ }^{[14 \mathrm{e}]}$
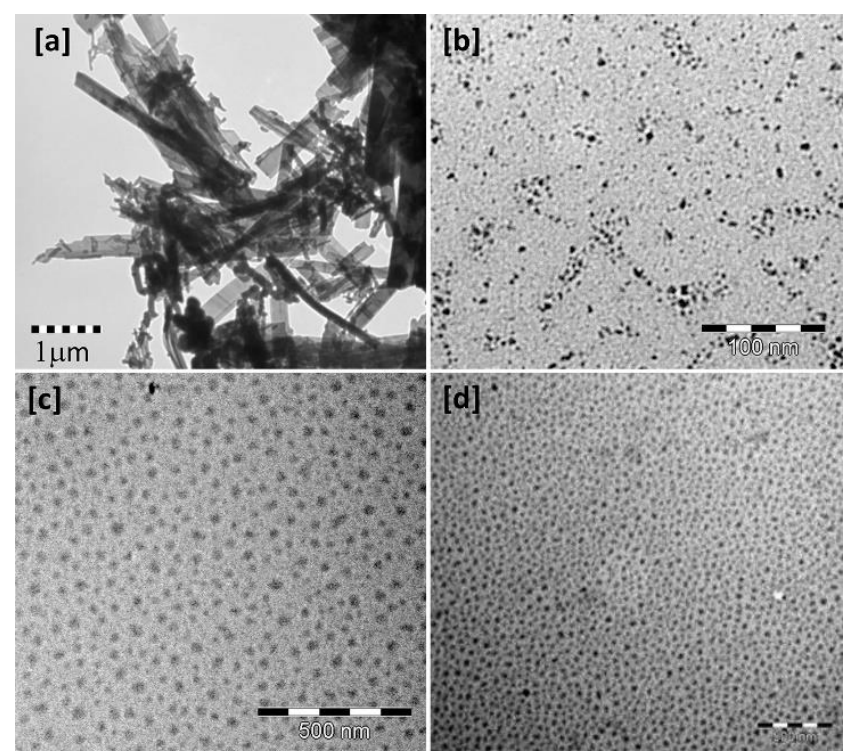

Figure 3. TEM images of TTF-TCNQ grown at room temperature: [a] without growth controller in acetonitrile (scale bar: $1 \mu \mathrm{m})$, [b] in presence of $(\mathrm{BMIM}) \mathrm{BF}_{4}$ : 20 eq. vs TTF in acetonitrile (scale bar: $100 \mathrm{~nm}$ ), [c] in presence of $n$ dodecylammonium lactobionate: 1 eq. vs TTF in THF (scale bar: $500 \mathrm{~nm}$ ). Reproduced from ref. ${ }^{[14 e]}$, Copyright (2013), with permission from the Royal Society of Chemistry (RSC) on behalf of the Centre National de la Recherche Scientifique (CNRS) and the RSC. [d] in presence of $n$-Oct: 1 eq. vs TTF in THF (scale bar: $500 \mathrm{~nm}$ ). Reproduced from ref. ${ }^{[14]}$, Copyright (2013), with permission from the American Chemical Society.

Temperature conditions. The temperature condition is another tunable factor for growing homogeneous nanoparticles, in particular when using imidazolium ionic liquids for which soft template effect is more effective at low temperature.

When TTF $\left[\mathrm{Ni}(\mathrm{dmit})_{2}\right]_{2}$ particles are prepared at room temperature in the presence of $\left(\mathrm{BMIM} \mathrm{BF}_{4}, 5 \%\right.$ of micrometer size platelets are present with a majority of elongated $(35-100 \mathrm{~nm})$ nanoparticles (Figure 4a). When the reaction is conducted at $-80{ }^{\circ} \mathrm{C}$, only spheroidal $(25 \mathrm{~nm})$ nanoparticles are observed. ${ }^{[14 a, 14 e, 15]}$ In addition to a more homogeneous morphology, the size of the particles is reduced (Figure $4 \mathrm{~b}$ ). (BMIM)BF 4 solidifies at $-71^{\circ} \mathrm{C}$. Below this temperature, the organization of this salt defines homogeneous open nanosize areas where the crystallization of the particles is constrained. ${ }^{[14 \mathrm{e}]}$

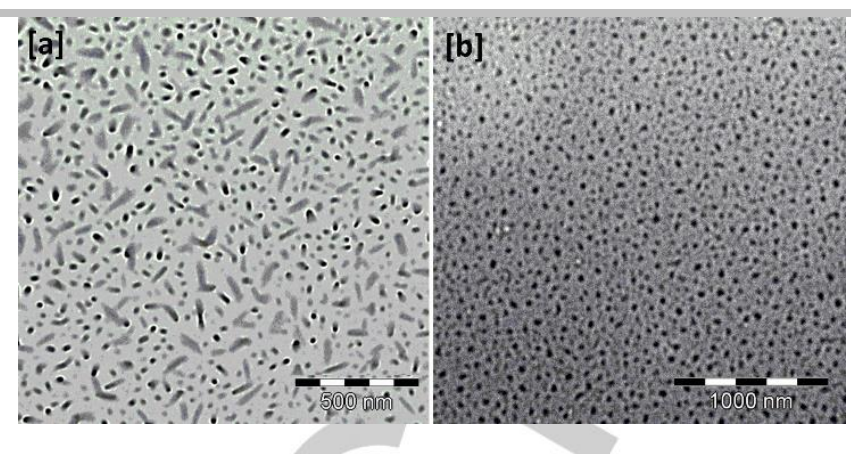

Figure 4. TEM images of TTF[Ni(dmit) $\left.)_{2}\right]_{2}$ nanoparticles prepared in

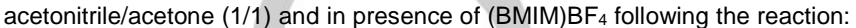
$\left(n-\mathrm{Bu}_{4} \mathrm{~N}\right)\left[\mathrm{Ni}(\mathrm{dmit})_{2}\right]+(\mathrm{TTF})_{3}\left(\mathrm{BF}_{4}\right)_{2}=\mathrm{TTF}\left[\mathrm{Ni}(\mathrm{dmit})_{2}\right]_{2}+2\left(n-\mathrm{Bu}_{4} \mathrm{~N}\right) \mathrm{BF}_{4}+2 \mathrm{TTF}$ [a] reaction at $25^{\circ} \mathrm{C}$ (scale bar: $500 \mathrm{~nm}$ ), [b] reaction at $-80^{\circ} \mathrm{C}$ (scale bar: 1000 $\mathrm{nm})$. Reproduced from ref. ${ }^{[14 a]}$, Copyright (2010), with permission from Elsevier and from ref. ${ }^{[14 e]}$, Copyright (2013), with permission of the Royal Society of Chemistry (RSC) on behalf of the Centre National de la Recherche Scientifique (CNRS) and the RSC.

Nanoparticles size control. In terms of size control, long-chain neutral molecules such as $\mathrm{N}$-octylfurfurylimine and its sulfur analog 1-octanamine- $\mathrm{N}$-(2-thienylmethylene) (Table $2[\mathrm{f}, \mathrm{g}]$ ) have shown high efficiency for growing small nanoparticles of $\mathrm{ET}_{2} \mathrm{l}_{3}$ by chemical oxidation using iodine: $30 \mathrm{~nm}$ large aggregates among which 2-6 nm nanoparticles are observed (Figure 5). ${ }^{[19]}$ Nanoparticles were larger, $85 \mathrm{~nm}$ and $40 \mathrm{~nm}$, when using dodecylamine and hexadecylamine, respectively. The efficiency of 1-octanamine-N-(2-thienylmethylene) can be explained by possible $\pi-\pi$ and S...S van-der Waals interactions, in addition to the long chain protection. Very small TTF-TCNQ nanoparticles (3$5 \mathrm{~nm}$ ) could also be isolated when $n$-octylamine was added to the TCNQ solution before reaction with TTF. ${ }^{[14]}$
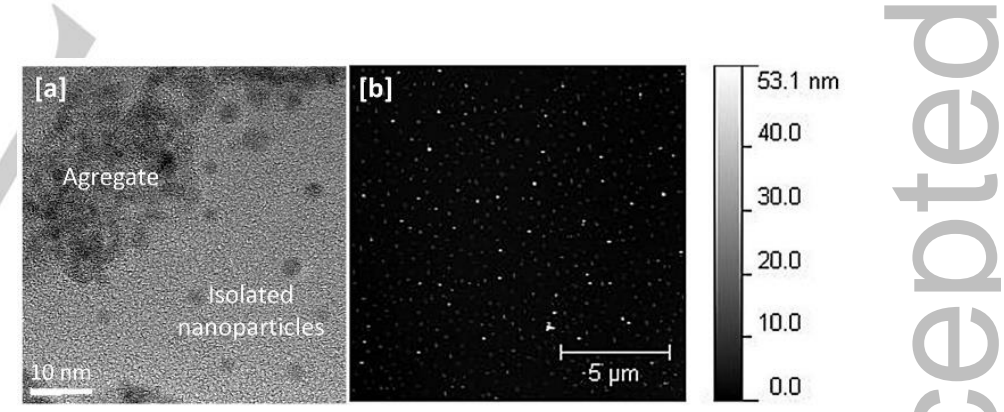

Figure 5. [a] TEM image of isolated nanoparticles $(2-6 \mathrm{~nm})$ of $E T_{2} l_{3}$ prepared in THF and stabilised with 1-octanamine-N-(2-thienylmethylene). An aggregate of nanoparticles is also observed. Reproduced from ref. ${ }^{[19]}$, Copyright (2016), with permission from the Royal Society of Chemistry. [b] AFM image of TTF-TCNQ nanoparticles $(3-5 \mathrm{~nm})$ obtained when $n$-Oct is reacted in THF with TCNQ prior to TTF. Reproduced from ref. ${ }^{[14 f]}$, Copyright (2013), with permission from the American Chemical Society.

Strong interactions. Stronger interactions between the growth controller and the material precursors were observed for TTFTCNQ nanoparticles stabilized by $n$-octylamine ${ }^{[14 f]}$ and Ni(ett) nanoparticles stabilized by (DMIM)BF ${ }_{4} \cdot{ }^{[22]} \mathrm{NMR}$ studies confirmed that $n$-octylamine substitutes for a CN group in TCNQ, leading to TCNQ-octylamine species. These species are present as a shell at the periphery of the TTF-TCNQ nanoparticles and improve their solubility: ${ }^{[14]}$ colloidal solution of TTF-TCNQ (10 g. L ${ }^{-1}$ in THF) can be prepared (Figure 6a). ${ }^{[14 d]}$ This observation 
WILEY-VCH

\section{MINIREVIEW}

recalls the formation of colloidal solutions of metal nanoparticles due to the coordination of same type of growth controllers to the metal center. ${ }^{[32]}$ Indeed, NMR studies also proved that determinant interactions between the metal ions and the growth controller govern the formation of nanoparticles of the $\mathrm{Ni}(\mathrm{ett})$

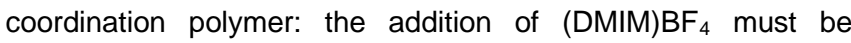
performed before the complexation of $\mathrm{Ni}^{2+}$ by ett ligands to obtain soluble nanoparticles of $\mathrm{Ni}$ (ett). ${ }^{[22]}$ Colloidal solutions of $\mathrm{Ni}$ (ett) (2 g. $\mathrm{L}^{-1}$ in acetone) are stable up to one month (Figure $6 \mathrm{~b}$ ). Yellow stable dispersions of $(\mathrm{TMTSF})_{2} \mathrm{PF}_{6}$ were obtained in acetonitrile at concentrations 10 times higher that of bulk crystals: $2.5 \mathrm{~g} . \mathrm{L}^{-1}$ for particle ${ }^{[17 b]}$ compared to 0.2 g. $\mathrm{L}^{-1}$ for crystals. ${ }^{[33]}$ An interesting feature was observed for solutions of $\mathrm{ET}_{2} \mathrm{I}_{3}$ in acetonitrile $(0.5 \mathrm{~g} . \mathrm{L}$ 1):[19] a reversible temperature dependent color dynamics from clear (low T) to yellow (high T) occurs when the solution is cycled between $23^{\circ} \mathrm{C}$ and $50^{\circ} \mathrm{C}$ suggesting a segregation/aggregation of the particles, as previously reported for DNA/Au nanoparticles assemblies. ${ }^{[34]}$

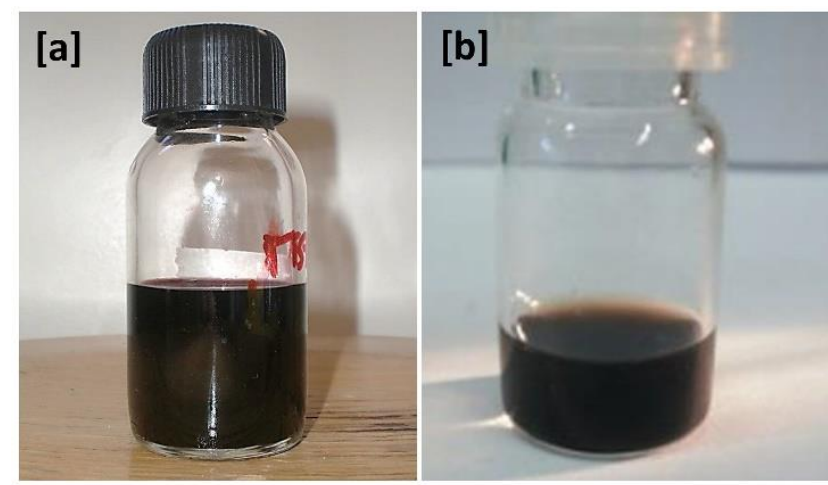

[c]

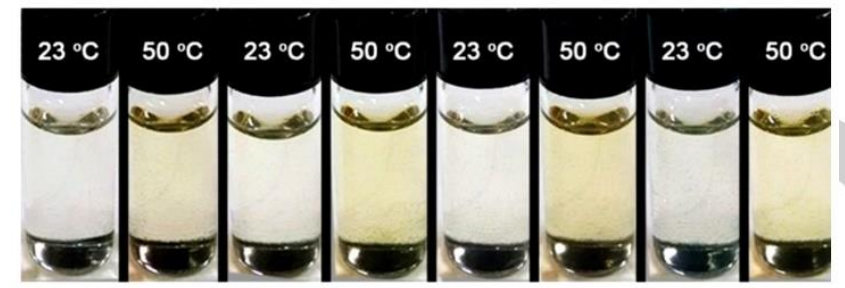

Figure 6. Colloidal solutions of [a] TTF-TCNQ $/ n$-Oct, $10 \mathrm{~g} \cdot \mathrm{L}^{-1}$ in THF Reproduced from ref..$^{[14 f]}$, Copyright (2013), with permission from the American Chemical Society; [b] Ni(ett)/(DMIM)BF 4 , 2 g. L $^{-1}$ in acetone. Reproduced from ref. ${ }^{[2]}$, Copyright (2013), with permission from Springer; [c] temperature cycling of a solution of $0.5 \mathrm{~g} . \mathrm{L}^{-1}$ of $\mathrm{ET}_{2} \mathrm{l}_{3} / 1$-octanamine- $\mathrm{N}$-(2-thienylmethylene) in acetonitrile. Reproduced from ref. ${ }^{[19]}$, Copyright (2016), with permission from the Royal Society of Chemistry.

\subsection{Electrochemical method}

As mentioned above, imidazolium salts and long chain ammonium salts combine the necessary characteristics to control the growth, act as supporting electrolyte and afford the counter ion of the expected phase for growing fractional oxidation state compounds by electrocrystallisation (Table 1). We have determined the best conditions for conducting the electrochemical growth of nanoparticles of a series of TTF-based molecular conductors $^{[17 b]}$ and will summarize them in this section.
Concentration of growth controller. The amount of growth controller, also acting as supporting electrolyte, should be set high enough to support the migration current. Usually set at 100 times that of the electroactive species for potentiostatic electrolysis, under the galvanostatic conditions applied to ensure a constant growth rate, this amount can be lowered, but not below 10 to obtain nanoparticles. ${ }^{[14 e, 17 b]}$ As shown in Figure $7 \mathrm{a}$, for a $\mathrm{TTF} / \mathrm{Me}(n-\mathrm{Oct})_{3} \mathrm{NCl}$ ratio of $1 / 3$, only needles $(2-10 \mu \mathrm{m})$ of $\mathrm{TTFCl}_{0.77}$ are formed, while spheroidal $(\sim 20 \mathrm{~nm})$ nanoparticles are obtained for a ratio of $1 / 10$ (Figure $7 b$ ).

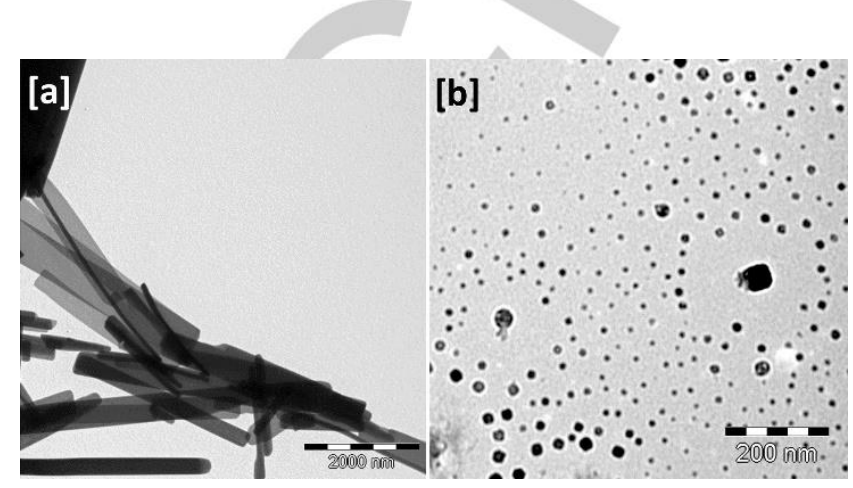

Figure 7. $\mathrm{TTFCl}_{0.77}$. [a] $\mathrm{TTF} / \mathrm{Me}(n-\mathrm{Oct})_{3} \mathrm{NCl}$ concentration ratio of $1 / 3$ in acetonitrile (scale bar: $2000 \mathrm{~nm}$ ). [b] TTF/Me $(n-\mathrm{Oct})_{3} \mathrm{NCl}$ concentration ratio of $1 / 10$ in acetonitrile (scale bar: $200 \mathrm{~nm}$ ). Reproduced from ref. ${ }^{[17 b]}$, Copyright (2016), with permission from Taras Shevchenko National University of Kyiv.

Stirring and high current densities. Under galvanostatic conditions, the constant growth rate ensures a homogeneous formation of particles. On the other hand, at low current densities, a limited quantity of material is obtained and after long electrolysis duration. In addition, passivation of the electrodes by the used bulky supporting electrolytes may occur. ${ }^{[35]}$ Through vigorous stirring to enhance the access of the electroactive species to the electrode and high current densities, the size and the morphology of $(\mathrm{TMTSF})_{2} \mathrm{PF}_{6}$ nanoparticles $(40-50 \mathrm{~nm})$ are not modified but the electrolysis duration is reduced from 3 days to $1 \mathrm{~h} \cdot{ }^{[17 \mathrm{~b}]}$ By combining a constant growth rate via galvanostatic conditions, a $1 / 10$ ratio between electroactive species and growth controller and stirring, nanoparticles of $\operatorname{TTFBr}_{0.59}(30 \mathrm{~nm}), \mathrm{ETCl}_{0.66}(50 \mathrm{~nm})$, $\mathrm{ET}_{2} \mathrm{Br}(40 \mathrm{~nm}),{ }^{[14 \mathrm{e}]}$ and $\left.\mathrm{ET}_{2}[\mathrm{Cu}(\mathrm{SCN}))_{2}(\sim 10 \mathrm{~nm})\right)^{[17 \mathrm{~b}]}$ were produced.

\subsection{Large-scale syntheses}

A typical synthesis affords $10-50 \mathrm{mg}$ of nanoparticles powder, a sufficient amount for conducting classical characterizations. For characterizations directly connected to potential applications and integration into components, larger amounts of material are required. The scale-up of syntheses was achieved by increasing the quantities of both the precursors and the solvent in order to work under the same concentration conditions, either the chemical or electrochemical route was used. This scale-up was done for TTF-TCNQ, $\mathrm{Et}_{2} \mathrm{I}_{3}, \mathrm{TTF}\left[\mathrm{Ni}(\mathrm{dmit})_{2}\right]_{2}$ and $\mathrm{ET}_{2} \mathrm{Cu}(\mathrm{NCS})_{2}$. By chemical route, $800 \mathrm{mg}$ of TTF-TCNQ/ $\left[\left(\mathrm{CH}_{3}\right)\left(n-\mathrm{C}_{8} \mathrm{H}_{17}\right)_{3} \mathrm{~N}\right] \mathrm{Cl}, 10 \mathrm{~g}$ of TTF-TCNQ/n-Oct, and $700 \mathrm{mg}$ of $\mathrm{Et}_{2} \mathrm{l}_{3} / 1$-octanamine-N-(2thienylmethylene) can be produced at one time. By electrochemical route, TTF[Ni(dmit $\left.)_{2}\right]_{2} /(\mathrm{BMIM})\left[\left(\mathrm{CF}_{3} \mathrm{SO}_{2}\right)_{2} \mathrm{~N}\right]$ and $\mathrm{ET}_{2} \mathrm{Cu}(\mathrm{NCS})_{2} / \mathrm{PEG} /(\mathrm{EMIM}) \mathrm{SCN}$ were prepared at $250 \mathrm{mg}$ amounts. 
WILEY-VCH

\section{General characteristics of nanoparticles of molecular conductors}

The morphology of nanoparticles clearly depends on the growth controller and on synthesis conditions. Although specific interactions between precursor molecules and growth controller can be predicted, no standard rules can be laid down for the production of homogenous nanoparticles: every system has to be studied following several synthesis conditions before identification of the best reproducible route. Indeed, when using the chemical procedure, the widest size distribution was between 5 and $70 \mathrm{~nm}$. Through modifying experimental conditions (nature or concentration of the growth controlling agent, solvent, temperature), the size distribution could be reduced to the 5-40 $\mathrm{nm}$ range. Furthermore, for the two systems which could be prepared by either the chemical or the electrochemical procedure, i.e. $\mathrm{TTF}\left[\mathrm{Ni}(\mathrm{dmit})_{2}\right]_{2}$ and $(\mathrm{ET})_{2}\left[\mathrm{Cu}(\mathrm{NCS})_{2}\right]$, size distributions were narrower for the electrochemical method $(5-25 \mathrm{~nm}$ range for $\operatorname{TTF}\left[\mathrm{Ni}(\mathrm{dmit})_{2}\right]_{2}$ (Figure S1) and 5-15 $\mathrm{nm}$ for $(\mathrm{ET})_{2}\left[\mathrm{Cu}(\mathrm{NCS})_{2}\right]$ (Figure S2).

The spheroidal nanoparticles thus produced show the same chemical composition of bulk crystals. Infrared and Raman spectra for nanoparticles allow the determination of, either the amount of charge transfer between donor and acceptor in CT compounds, or the partial charge borne by the TTF-based moiety in FC compounds. Values agree with those for bulk phases. For TTF-TCNQ/n-Oct, infrared spectra exhibit additional features corresponding to charge states different from those in the bulk. ${ }^{[14]}$ Additional bands are due to TCNQ-octylamine species at the nanoparticle surface. For CT compounds grown as nanoparticles in the presence of ionic liquids with an anion containing fluorine atoms, i.e. $\mathrm{BF}_{4}^{-}$and $\left[\left(\mathrm{CF}_{3} \mathrm{SO}_{2}\right)_{2} \mathrm{~N}\right]^{-}$, X-ray photoelectron spectroscopy confirm the donor to acceptor stoichiometry. ${ }^{[14 a]}$ This technique also evidences the presence of ionic liquid as a thin protecting layer around the particles, preventing their aggregation. ${ }^{[14 a]}$

XRD on powder is an efficient tool for determining the purity of the obtained compounds. Simple comparison of the XRD spectra of the bulk and the one of the NP allows to check whether the synthesis has not been perturbated by the addition of the growth controller, leading for instance to polyphasic materials. Some care must be pointed out, mainly with electrochemical synthesis: preferred orientations can occur, which lead to significant changes in the relative intensity of the peaks. But simple refinement allows to check the unicity of the synthesized compound.

Note that a high degree of crystallinity of individual particles of $\mathrm{Et}_{2} \mathrm{l}_{3}{ }^{[19]}$ and $(\mathrm{TMTSF})_{2} \mathrm{ClO}_{4}{ }^{[15 \mathrm{~b}]}$ (Figure 8a) was observed. Welldispersed nanoparticles can be isolated but aggregation may occur. Indeed, spheroidal nanoparticles of molecular conductors that generally grow as needles, are metastable and subject to any association that reproduces elongated objects. In a few cases, aggregation results in a super-organization of the particles: nanosticks of $\mathrm{TTFBr}_{0.56}{ }^{[18]}$ (Figure $8 \mathrm{~b}$ ) or stacks of hexagonal superstructures for $\mathrm{Et}_{2}\left[\mathrm{Cu}(\mathrm{NCS})_{2}\right]$ (Figure S3). Such associations are facilitated when the particles are not protected by the growth controller. On the other hand, when a shell of growth controller is present at the surface of the particles, they are well-dispersed. The smaller size and best dispersion were obtained for TTF$\mathrm{TCNQ} / n$-Oct nanoparticles with size of $5.2 \pm 0.4 \mathrm{~nm}$. This value and the standard deviation are extremely small for molecular conductors and compete well with values obtained for 3-D materials such as metal nanoparticles ${ }^{[32]}$ or Prussian Blue compounds. ${ }^{[31]}$

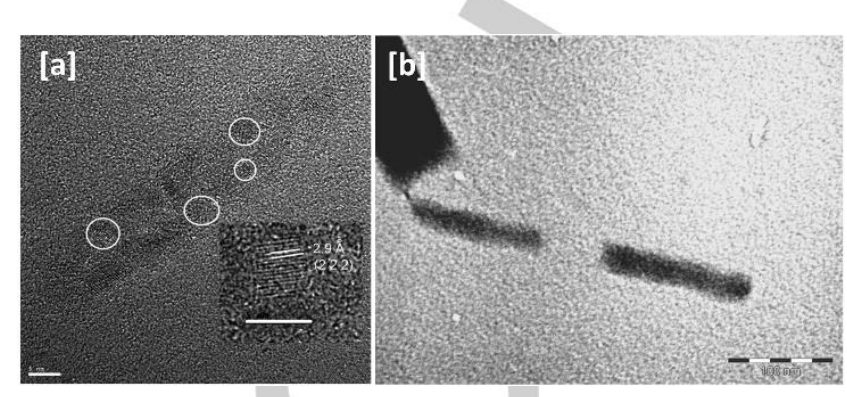

Figure 8. [a] HRTEM image of 3-5 nm aggregated crystalline nanoparticles of (TMTSF) $)_{2} \mathrm{ClO}_{4} /\left[\mathrm{Me}(n-\mathrm{Oct})_{3} \mathrm{~N}\right] \mathrm{ClO}_{4}$, Inset: one indexed $4.5 \mathrm{~nm}$ nanoparticle, (scale bar $=5 \mathrm{~nm}$ ). Reproduced from ref. ${ }^{[15 \mathrm{~b}]}$; [b] High magnification TEM image of $\mathrm{TTFBr}_{0.56} / \mathrm{PEDOT}$ nanosticks resulting from a super-organization of particles (scale bar $=100 \mathrm{~nm})$. Reproduced from ref. ${ }^{[18]}$, Copyright (2011), with permission from Elsevier.

\section{Physical properties of nanoparticles of molecular conductors}

One of the aims for growing nanoparticles of molecular conductors was to evaluate the effect of the size reduction on their transport properties, in particular down to which size superconductivity will be able to develop within the material.

As soon as the material size is reduced and whatever the morphology, fiber-like or nanoparticles, thermally activated transport properties are classically observed due to grainboundaries. Nevertheless, we reported that deposits made of bundles of micrometric fibers of TTF[Ni(dmit $\left.)_{2}\right]_{2}$ exhibit superconductivity at $0.8 \mathrm{~K}$ under $7.7 \mathrm{kbar}$, values in agreement with those measured on macroscopic single crystals $(1.6 \mathrm{~K}$ under 7 kbar). ${ }^{[12]}$ Fiber-like deposits of $(\mathrm{TMTSF})_{2} \mathrm{ClO}_{4}$ also exhibit a thermally activated electric behavior, but the well-known anionordering transition clearly occurs at $25 \mathrm{~K}$, as the signature of the stabilization of a superconducting state at lower temperatures. ${ }^{[13]}$ At nanoscale, current-voltage curves of individual nanoparticles or aggregates of nanoparticles of $\mathrm{Et}_{2} \mathrm{I}_{3},{ }^{[19]} \mathrm{Et}_{2}\left[\mathrm{Cu}(\mathrm{NCS})_{2}\right]^{[20 a]}$, $\operatorname{Per}_{2}\left[\mathrm{Au}(\mathrm{mnt})_{2}\right]^{[16]}$ (Figure 9a) and $\kappa(\mathrm{BETS})_{2} \mathrm{FeCl}_{4}$ (Figure S4) have been measured using conductive AFM. They are characterized by a nonlinear current-voltage behavior due to the resistance contribution of grain boundaries to the overall conductivity: activation energies are nevertheless very low, 1.52, $0.95,0.26$ and $1.30 \mathrm{eV}$, respectively. This is similar to what has been observed for fiber-like materials but does not prevent superconductivity to occur. Indeed, inductive magnetic susceptibility measurements of nanoparticles of (TMTSF) $)_{2} \mathrm{ClO}_{4}$ of size 3-5 nm, evidence superconductivity below $1.2 \mathrm{~K}$, consistent with single crystals properties. ${ }^{[15 b]}$ Nanoparticle assembly of (TMTSF) ${ }_{2} \mathrm{PF}_{6}$, characterized by $30-60 \mathrm{~nm}$ aggregates of $3-5 \mathrm{~nm}$ particles, exhibit the same SDW ground state of a single crystal, including all characteristic features of this phase. ${ }^{[21 b]}$ Interestingly, a pellet made of 2-6 nm nanoparticles of $\mathrm{Et}_{2} \mathrm{I}_{3}$ show a robust metallic behavior and a superconducting transition at $T c \sim 7.5 \mathrm{~K}$ confirmed from both electrical resistance (Figure 9b) and SQUID magnetic susceptibility measurements. ${ }^{[19]}$ SQUID measurements of $30 \mathrm{~nm}$ nanoparticles of $\mathrm{Et}_{2}\left[\mathrm{Cu}(\mathrm{NCS})_{2}\right]$ also confirmed the occurrence of the superconducting transition at $T C \sim 9.1 \mathrm{~K}$, close 


\section{WILEY-VCH}

\section{MINIREVIEW}

to the one observed on single crystals $(9.5 \mathrm{~K}) \cdot{ }^{[20 \mathrm{~b}]}$ These results indicate that the effective coherence length within these nanomaterials is comparable or smaller than the effective nanoparticle size. Therefore, superconductivity can establish in nanoparticles as small as $2-6 \mathrm{~nm}$
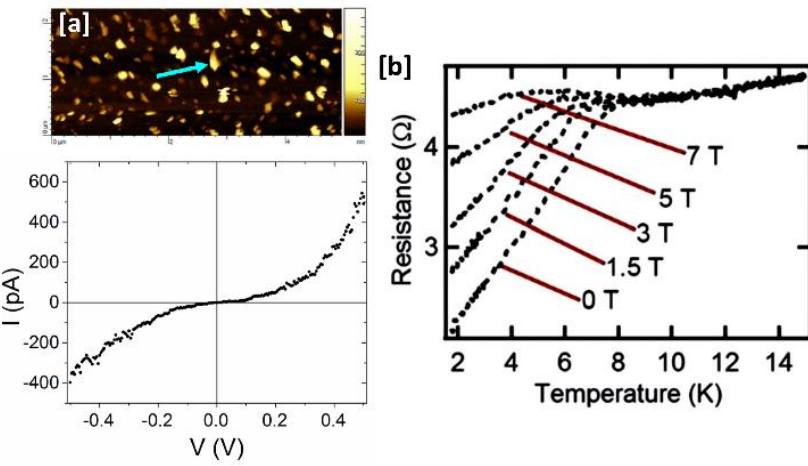

Figure 9. [a] AFM topographic image of $\mathrm{Per}_{2}\left[\mathrm{Au}(\mathrm{mnt})_{2}\right]$ and $I-\mathrm{V}$ curve of a 40 $\mathrm{nm}$ high nanoparticle indicated by the arrow. Reproduced from ref. ${ }^{[16]}$, Copyright (2020), with permission from the Académie des Sciences, Paris; [b] Temperature dependent resistance of $\mathrm{Et}_{2} \mathrm{l}_{3}$ nanoparticles at various magnetic fields up to $7 \mathrm{~T}$ confirming a superconducting transition for all applied fields. Reproduced from ref. ${ }^{[19]}$, Copyright (2016), with permission from the Royal Society of Chemistry.

\section{Towards applications of molecular conductors as nanoparticles}

Nanoparticles of molecular conductors can act as conductive charge within composite materials, be used for drawing electrical nanocircuits or as deposits for the dissipation of surface charging. Colloidal solutions facilitate the production of homogeneous dispersion within the composite matrix or the deposits using inkjet or spray coating process on surfaces.

\subsection{Composite materials and deposits}

Figure 10 shows two examples of the incorporation of TTF-TCNQ nanoparticles within a composite and onto surfaces through the use of their colloidal solution.

TTF-TCNQ nanoparticles have been integrated into composites for spatial applications (Figure 10a). The results showed that the expected performance was in line with and in favor of lighter structures compared to the materials classically used for the desired applications: consistent thermal stability, similar electronic properties for much lower loadings ( $9 \%$ with TTF-TCNQ compared to $50 \%$ for currently used materials). By spray-coating, a large surface area of an alumina substrate could also be homogenously covered by a thick deposit $(90 \mu \mathrm{m})$ of TTF-TCNQ nanoparticles (Figure 10b). ${ }^{[14 f]}$
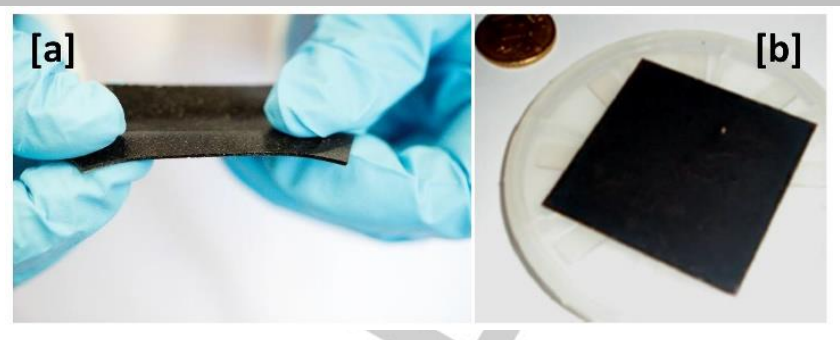

Figure 10. [a] Composite containing $5 \%$ wt. of TTF-TCNQ nanoparticles in a space-qualified resin, thickness: $0.4 \mathrm{~mm}$. CFrédéric MALIGNE/LCC/CNRS Photothèque, Copyright (2018), with permission from CNRS Photothèque. [b] Alumina substrate $(5 \mathrm{~cm} \times 5 \mathrm{~cm})$ covered by a continuous deposit of TTF-TCNQ nanoparticles, thickness $=90.00 \pm 0.04 \mu \mathrm{m}$. Reproduced from ref. ${ }^{[14 f]}$, Copyright (2013), with permission from the American Chemical Society.

\subsection{Organic field effect transistors}

Organic materials have high potential for applications in electronic devices because they offer advanced mechanical characteristics in favor of flexible devices. They have been widely studied as structure components for organic field effect transistors (OFETs). ${ }^{[36]}$ The OFETs structure is generally built by vapordeposition of the components. Among organic metals, TTF-TCNQ can be vapor-deposited ${ }^{[37]}$, inkjet-printed ${ }^{[38]}$ or spray-coated ${ }^{[39]}$ but a solution technique must be used for other non-vaporizable materials. Double-inkjet printing ${ }^{[40]}$ can be applied but it implies a reactive step which may be difficult to control. As nanoparticles of TTF-TCNQ, TTF[Ni(dmit) $)_{2}$ and $\mathrm{ET}_{2} \mathrm{l}_{3}$ were available as stable dispersions, single-shot inkjet printing ${ }^{[41]}$ could be used to make bottom contacts of OFETs with these materials. High conducting films and good performance pentacene, sexithiophene and $\mathrm{C}_{60}$ based OFETs were obtained. ${ }^{[14 b, 14 c]}$ These features are explained by enhanced interface properties afforded through morphological continuity, reduction of the contact resistance and absence of interfacial potential. ${ }^{[42]}$ Figure 11a gives an example of the smooth continuous surface of a TTF $\left[\mathrm{Ni}(\mathrm{dmit})_{2}\right]_{2}$ electrode associated with a pentacene channel and Figure $11 \mathrm{~b}$ shows the transfer characteristics of one of the pentacene/TTF-TCNQ OFETs.
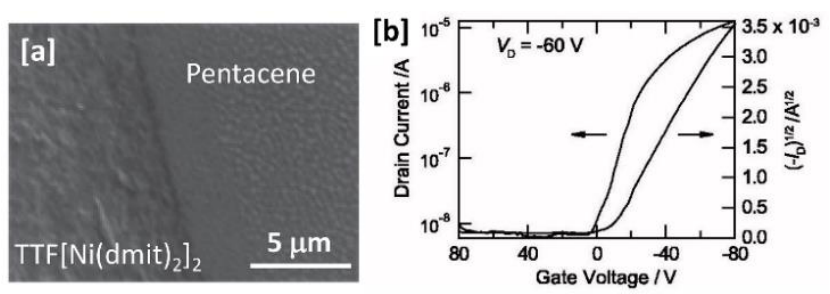

Figure 11. [a] SEM image of a boundary of TTF[Ni(dmit $\left.)_{2}\right]_{2}$ electrode and pentacene channel regions. Reproduced from ref. ${ }^{[14 c]}$, Copyright (2011), with permission from the Royal Society of Chemistry. [b] Transfer characteristics of pentacene OFETs with source/drain electrodes made from TTF-TCNQ nanoparticles. Reproduced from ref. ${ }^{[14 b]}$, Copyright (2011), with permission from the Royal Society of Chemistry (RSC) on behalf of the Centre National de la Recherche Scientifique (CNRS) and the RSC.

\subsection{Thermoelectricity}

Converting wasted-heat into electricity is of high concern for energy saving and environmental purpose. The efficiency of a thermoelectric material is given by its dimensionless figure of 
WILEY-VCH

\section{MINIREVIEW}

merit $Z T$ calculated from $Z T=S^{2} \sigma T / \lambda$ where $S$ is the Seekeck coefficient, $\sigma$ the electrical conductivity, $T$ the absolute temperature and $\lambda$ the thermal conductivity. Metal chalcogenides are among the most studied systems for heat recovery. ${ }^{[43]}$ Commercialized bulk materials are $\mathrm{Bi}_{2} \mathrm{Te}_{3}$ and its alloys such as $\mathrm{Bi}_{x} \mathrm{Sb}_{2-x} \mathrm{Te}_{3}$ and have $Z T$ around 1. Nanocrystalline powders of these materials show improved $\mathrm{ZT}$ values due to lower thermal conductivity, either they are produced through mechanical grinding ${ }^{[44]}$ or by a wet chemical method. ${ }^{[45]}$

Other families of thermoelectric materials showing encouraging performances include organic polymers ${ }^{[46]}$ such as poly(3,4ethylenedioxythiophene) (PEDOT) and metalorganic polymeric materials as $\mathrm{Ni}(\mathrm{ett})^{[47]}$ and $\mathrm{Ni}\left(\mathrm{tto}^{[47 \mathrm{~b}]}\right.$ (Figure 1). These materials have been studied as substitutes for metal chalcogenides because they are more environment-friendly due to lower toxicity, have lighter weight and make possible the production of largearea flexible devices. To our knowledge, their thermoelectric properties have not been measured in the form of nanoparticles. The conductivity of $\mathrm{Ni}(\mathrm{ett}) /\left(\mathrm{BMIM} \mathrm{BF}_{4}\right.$ nanoparticles ${ }^{[22]}$ is much lower compared to the bulk polymer ${ }^{[47 a]}: 10^{-3}-10^{-5} \mathrm{~S}^{-\mathrm{cm}^{-1}}$ and 1-50 $\mathrm{Scm}^{-1}$, respectively. More encouraging is the conductivity of $\mathrm{Ni}($ tto $) / \mathrm{PEG}\left(0.8 \mathrm{~S}^{-\mathrm{cm}^{-1}}\right)^{[23]}$ which is only slightly lower compared to the bulk material $\left(30-50 \mathrm{~S} . \mathrm{cm}^{-1}\right)^{[47 \mathrm{~b}]}$, thus deserving further measurements for the evaluation of $Z T$.

Charge transfer compounds, including TTF-TCNQ, were also evaluated as potential thermoelectric materials. ${ }^{[48]}$ Among those isolated as nanoparticles, we have measured the thermoelectric properties of $\mathrm{ET}_{2} \mathrm{I}_{3}{ }^{[19]}$ This p-type material has a Seebeck coefficient of $30 \mu \mathrm{V} . \mathrm{K}^{-1}$, alike the value determined previously by Bender et al. ${ }^{[49]}$ Nevertheless, due to the lack of data concerning the $\mathrm{ZT}$ value of $\mathrm{ET}_{2} \mathrm{l}_{3}$ on single crystal, the influence of the nanostructuration cannot be evaluated. $\mathrm{ET}_{2} \mathrm{I}_{3}$ nanoparticles combine: (i) a Seebeck value in the same absolute range as $n$ type TTF-TCNQ crystalline powder ${ }^{[48]}$ and significantly higher than PEDOT-based materials, ${ }^{[46]}$ (ii) a high conductivity of $10 \mathrm{~S} . \mathrm{cm}^{-1}$ at $300 \mathrm{~K}$ and (iii) a thermal conductivity of $0.175 \mathrm{~W} \cdot \mathrm{m}^{-1} \cdot \mathrm{K}^{-1}$ at $300 \mathrm{~K}$, comparable to TTF-TCNQ although one order of magnitude lower than $\mathrm{Bi}-\mathrm{Sb}$-Te alloys. These values lead to a $Z T$ of $1.47 \times 10^{-3}$, that is 10 times larger than that of TTFTCNQ crystalline powder $\left(1.83 \times 10^{-4}\right),{ }^{[48]}$ confirming the interest of the nanostructuration of thermoelectric materials.

\subsection{Biomaterials}

Diagnosis and curing devices based on nanomaterials are attracting high interest. ${ }^{[50]}$ While nanomaterials based on metals, metal chalcogenides, metal-organic frameworks or carbon are commonly reported for applications in biological devices, the application of molecular conductors appears to be limited to bulk TTF-TCNQ in the field of biosensors. ${ }^{[51]}$ Nevertheless, only the building molecules of this phase, i.e. separate TTF and TCNQ, were studied in terms of cytotoxicity, probably because of the nonsolubility of the adduct. ${ }^{[52]}$ Therefore, as soluble nanoparticles of TTF-TCNQ were available and, as the adduct is chemically different from its precursors and will consequently interact differently with external media, before including it into biological devices, we performed the study of the cytotoxicity of as-prepared TTF-TCNQ/n-Oct nanoparticles and of these particles further covered by a biological active species (trans-2-decenoic acid). ${ }^{[14 h]}$ Both type of nanoparticles form stable solutions in ethanol at a concentration up to $2.5 \mathrm{~g} . \mathrm{L}^{-1}$ without modification in size (Figure
12). Cytotoxicity results evidence that these TTF-TCNQ nanoparticles do not induce cell death both for normal cells (human dermal fibroblasts) and cancer cells (HCT-116), up to concentrations suitable for later use as biocompatible and conducting soluble nanoparticles in biomedical devices. ${ }^{[14 \mathrm{~h}]}$

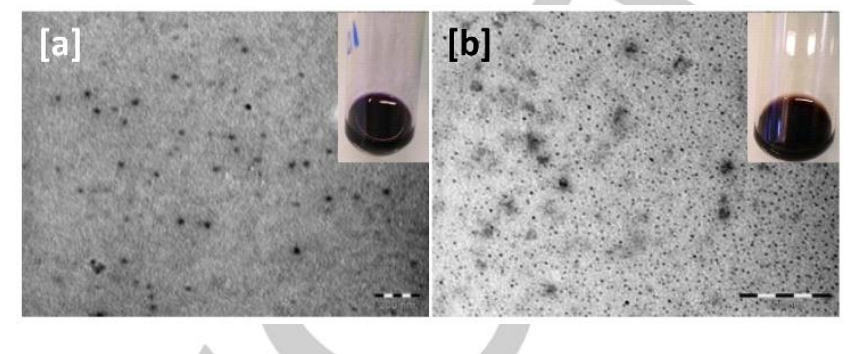

Figure 12.TEM images of [a] TTF-TCNQ $/ n$-Oct and [b] TTF-TCNQ $/ n$-Oct $/$ trans 2-decenoic acid nanoparticles from the $2.5 \mathrm{~g} . \mathrm{L}^{-1}$ solutions in ethanol (inserts) scale bars $=200 \mathrm{~nm}$. Adapted from ref. ${ }^{[14 \mathrm{~h}]}$, Copyright (2020), with permission from The Royal Society of Chemistry.

\section{Conclusion}

To meet the need for integration into commercially available devices, a material must associate matter, property and functionality. Due to their organic-based composition, molecular conductors and superconductors have mainly been studied for their intriguing physical properties. Indeed, physical studies remain very active for understanding their conductive properties. On the other hand, due to the still recent discovery (1970's) of these materials, less studies have been conducted to explore their potential applications. For evaluating their functionality, molecular conductors have to be processed as thin films or uniformly included within a composite matrix. Unfortunately, the usual techniques of microelectronics, such as vapor or spray deposition, cannot be applied to conventionally synthesized bulk materials, because a very few can be vaporized or solubilized. Following the successful reports on the production of colloidal solutions of metals or metal oxides nanoparticles using growth controlling molecules, we have explored synthetic procedures that could lead to nanoparticles of molecular conductors and superconductors.

This review gathers the various conditions investigated for growing nanoparticles of molecular conductors, according to the synthesis procedure (chemical or electrochemical) to be applied for each material. We studied the addition of three families of growth controlling agents: ionic liquids, long-chain ammonium salts, and neutral amphiphilic molecules.

From our results, we can sort out some characteristic features:

- The growth controllers establish efficient ionic/covalent $/ \pi$ overlapping interactions with the reactive species to limit growth. The strength of these interactions is significant in promoting the formation of colloidal solutions.

Although the one-dimensional character of molecular conductors is not favorable to their growth as spheroidal objects, well-dispersed particles, from 2 to $50 \mathrm{~nm}$ in size, were successfully isolated.

- For each material, many different concentrations of growth controller must be investigated to reach the appropriate conditions for growing the smallest and best-dispersed nanoparticles. 
WILEY-VCH

- Electrochemical syntheses of fractional oxidation state materials such as (TMTSF) ${ }_{2} \mathrm{ClO}_{4}$ can be conducted without unwanted species, the growth controller acting both as supporting electrolyte and provider of the counter ion and the growth controller.

No incidence is observed on the chemical composition and structure of the nanoparticles compared to single crystals at the particle size obtained, as low as $2 \mathrm{~nm}$.

- The resistive effect of the grain boundaries weakens the transport properties of nanoparticle powders as in the case of microcrystalline powders, but they do not prevent superconductivity to occur in nanoparticles of (TMTSF) ${ }_{2} \mathrm{ClO}_{4}$, $\mathrm{Et}_{2} \mathrm{I}_{3}$ and $\mathrm{Et}_{2}\left[\mathrm{Cu}(\mathrm{NCS})_{2}\right]$.

Scale-up of some syntheses was performed and afforded 20 to 1000 times the original amounts, a valuable point for potential applications.

During the past ten years, we prepared and studied the chemical and physical properties of fourteen molecular conductors or superconductors of three families: charge-transfer salts, fractional oxidation state compounds and coordination polymers. We could also evaluate the potential application of these new nanomaterials in four domains: composite materials, field effect transistors, thermoelectric components and biomedical materials. We hope that the acquired knowledge reviewed here would encourage further investigations for applications of these materials now available as soluble or dispersible powders.

\section{Acknowledgements}

This work was supported by CNRS and grants from the French Ministry of Higher Education and Research, CNES and EU funding. We thank F. Viala (IPBS/CNRS/Universite de Toulouse) for her technical assistance in the finalization of the illustrations.

\section{Conflict of Interest}

The authors declare no conflict of interest.

Keywords: molecular conductors $\cdot$ nanoparticles $\bullet$ organic superconductors $\cdot$ colloidal solutions $\cdot$ coordination polymers size-controlling agent

[1] a) L. B. Coleman, M. J. Cohen, D. J. Sandman, F. G. Yamagishi, A. F. Garito, A. J. Heeger, Solid State Communications 1973, 12, 11251132; b) M. J. Cohen, L. B. Coleman, A. F. Garito, A. J. Heeger, Physical Review B 1974, 10,1298-1307; c) J. Ferraris, D. O. Cowan, V. Walatka, J. H. Perlstein, Journal of the american chemical society 1973, 95, 948-949.

[2] L. Valade, H. Tanaka, in Molecular Materials (Eds.: D. W. Bruce, R. Walton), John Wiley \& Sons Ltd, Chichester, UK, 2010, pp. 215-290.

[3] D. Jérome, A. Mazaud, M. Ribault, K. Bechgaard, J. Physique Lett. 1980, 41, 95-98

[4] a) K. Bechgaard, K. Carneiro, F. B. Rasmussen, M. Olsen, G. Rindorf, C. S. Jacobsen, H. J. Pedersen, J. C. Scott, Journal of the American Chemical Society 1981, 103, 2440-2442; b) K. Bechgaard, K. Carneiro, M. Olsen, F. B. Rasmussen, C. S. Jacobsen, Physical Review Letters 1981, 46, 852-855.

[5] T. Komatsu, T. Nakamura, N. Matsukawa, H. Yamochi, G. Saito, H. Ito T. Ishiguro, M. Kusunoki, K. Sakaguchi, Solid State Communications 1991, 80, 843-847.

[6] a) L. Brossard, M. Ribault, L. Valade, P. Cassoux, Physica B \& C 1986 143, 378-380; b) L. Brossard, M. Ribault, M. Bousseau, L. Valade, P. Cassoux, Comptes Rendus de l'Académie des Sciences 1986, 302-II, 205-210; c) M. Bousseau, L. Valade, J. P. Legros, P. Cassoux, M. Garbauskas, L. V. Interrante, Journal of the American Chemical Society 1986, 108, 1908-1916.
[7] H. Tanaka, Y. Okano, H. Kobayashi, W. Suzuki, A. Kobayashi, Science 2001, 291, 285-287.

[8] H. B. Cui, H. Kobayashi, S. Ishibashi, M. Sasa, F. Iwase, R. Kato, A. Kobayashi, Journal of the American Chemical Society 2014, 136, 76197622 .

[9] a) T. Ishiguro, K. Yamaji, G. Saito, Organic Superconductors, Vol. 88 Springer, Berlin, 1998; b) H. Kobayashi, A. Kobayashi, H. Tajima, Chemistry-an Asian Journal 2011, 6, 1688-1704.

[10] a) L. Valade, D. de Caro, M. Basso-Bert, I. Malfant, C. Faulmann, B. G. De Bonneval, J. P. Legros, Coordination Chemistry Reviews 2005, 249, 1986-1996; b) D. de Caro, M. Basso-Bert, H. Casellas, M. Elgaddari, J. P. Savy, J. F. Lamere, A. Bachelier, C. Faulmann, I. Malfant, M. Etienne, L. Valade, Comptes Rendus Chimie 2005, 8 , 1156-1173; c) L. Valade, D. de Caro, I. Malfant, in Organic Conductors, Superconductors and Magnets: From synthesis to Molecular Electronics, Vol. 139 (Eds.: L. Ouahab, E. B. Yagubskii), Kluwer Acad. \& NATO Sci. Ser. II, Dordrecht, 2004, pp. 241-268.

[11] a) D. de Caro, in Nanowires - Fundamental Research (Ed.: A. Hashim), INTECH, 2011, pp. 509-526; b) T. Sugimoto, H. Tanaka, D. de Caro, L. Valade, Materials 2010, 3, 1640-1673; c) L. Valade, H. Casellas, S. Roques, C. Faulmann, D. de Caro, A. Zwick, L. Ariès, Journal of Solid State Chemistry 2002, 168, 438-443; d) J. P. Savy, D. de Caro, C. Faulmann, L. Valade, M. Almeida, T. Koike, H. Fujiwara, T. Sugimoto, J. Fraxedas, T. Ondarçuhu, C. Pasquier, New Journal of Chemistry 2007, 31, 519-527.

[12] J. P. Savy, D. De Caro, L. Valade, J. P. Legros, P. Auban-Senzier, C. R. Pasquier, J. Fraxedas, F. Senocq, Europhysics Letters 2007, 78.

[13] J.-P. Savy, D. de Caro, L. Valade, J.-C. Coiffic, E. S. Choi, J. S. Brooks, J. Fraxedas, Synthetic Metals 2010, 160, 855-858.

[14] a) D. de Caro, K. Jacob, C. Faulmann, J. P. Legros, F. Senocq, J. Fraxedas, L. Valade, Synthetic Metals 2010, 160, 1223-1227; b) D. de Caro, K. Jacob, H. Hahioui, C. Faulmann, L. Valade, T. Kadoya, T. Mori, J. Fraxedas, L. Viau, New J. Chem. 2011, 35, 1315-1319; c) T. Kadoya, D. de Caro, K. Jacob, C. Faulmann, L. Valade, T. Mori, Journal of Materials Chemistry 2011, 21, 18421-18424; d) M. Souque, O. Vendier, L. Valade, D. de Caro, J.-M. Desmarres, F. Courtade, Patent FR 2957460, 2011; e) D. de Caro, L. Valade, C. Faulmann, K. Jacob, D. Van Dorsselaer, I. Chtioui, L. Salmon, A. Sabbar, S. El Hajjaji, E. Perez, S. Franceschi, J. Fraxedas, New Journal of Chemistry 2013, 37, 3331-3336; f) D. de Caro, M. Souque, C. Faulmann, Y. Coppel, L. Valade, J. Fraxedas, O. Vendier, F. Courtade, Langmuir 2013, 29, 8983-8988; g) D. De Caro, C. Faulmann, L. Valade, L'Actualité Chimique 2018, 11-16; h) H. Chen, G. Albérola, D. de Caro, C. Faulmann, M. Golzio, L. Valade, M.-P. Rols, Materials Advances 2020, https://doi.org/10.1039/DOMA00129E.

[15] a) D. de Caro, K. Jacob, C. Faulmann, L. Valade, L. Viau, Comptes Rendus Chimie 2012, 15, 950-954; b) D. de Caro, C. Faulmann, L. Valade, K. Jacob, I. Chtioui, S. Foulal, P. de Caro, M. Bergez-Lacoste, J. Fraxedas, B. Ballesteros, J. S. Brooks, E. Steven, L. E. Winter, European Journal of Inorganic Chemistry 2014, 2014, 4010-4016.

[16] D. de Caro, K. Jacob, C. Faulmann, M. Tassé, L. Valade, Comptes Rendus Chimie 2020, 23, https://doi.org/10.5802/crchim.24. a) D. de Caro, K. Jacob, S. Mazzi, M.-T. Carayon, C. Faulmann, L. Valade, Synthetic Metals 2012, 162, 805-807; b) D. de Caro, C. Faulmann, L. Valade, K. Jacob, B. Cormary, French-Ukrainian Journal of Chemistry 2016, 4, 65-75.

[18] M. Souque, D. de Caro, L. Valade, Synthetic Metals 2011, 161, 10011004.

[19] I. Chtioui-Gay, C. Faulmann, D. de Caro, K. Jacob, L. Valade, P. de Caro, J. Fraxedas, B. Ballesteros, E. Steven, E. S. Choi, M. Lee, S. M. Benjamin, E. Yvenou, J. P. Simonato, A. Carella, Journal of Materials Chemistry C 2016, 4, 7449-7454

[20] a) B. Cormary, C. Faulmann, D. de Caro, L. Valade, P. de Caro, B. Ballesteros, J. Fraxedas, Comptes Rendus Chimie 2018, 21, 809-813; b) M. Revelli Beaumont, C. Faulmann, D. de Caro, M. Cazayous, Y. Gallais, A. Sacuto, C. Pasquier, P. Auban Senzier, M. Monteverde, K. Jacob, L. Valade, Synthetic Metals 2020, 261, 116310

[21] a) D. de Caro, K. Jacob, C. Faulmann, L. Valade, Comptes Rendus Chimie 2013, 16, 629-633; b) L. E. Winter, E. Steven, J. S. Brooks, S. Benjamin, J.-H. Park, D. de Caro, C. Faulmann, L. Valade, K. Jacob, I. Chtioui, B. Ballesteros, J. Fraxedas, Physical Review B 2015, 91, 035437 .

[22] C. Faulmann, J. Chahine, K. Jacob, Y. Coppel, L. Valade, D. Caro, Journal of Nanoparticle Research 2013, 15, 1586

[23] C. Faulmann, B. Cormary, D. de Caro, K. Jacob, L. Valade, P. de Caro Journal of Materials Science and Chemical Engineering, 2020, 8, 1-12.

[24] L. Valade, D. de Caro, J. P. Savy, I. Malfant, C. Faulmann, M. Almeida, J. Fraxedas, J. S. Brooks, Journal of Low Temperature Physics 2006 , $142,397-400$.

[25] T. Gutel, C. C. Santini, K. Philippot, A. Padua, K. Pelzer, B. Chaudret, Y. Chauvin, J.-M. Basset, Journal of Materials Chemistry 2009, 19, 3624-3631.

[26] M. L. Calzada, S. Gross, Chemistry - A European Journal 2020, 26, 9039-9040. 
WILEY-VCH

\section{MINIREVIEW}

[27] D. de Caro, C. Faulmann, L. Valade, in Molecular Materials (Eds.: S. V. Malhotra, B. L. V. Prasad, J. Fraxedas), CRC Press, 2017, pp. 127 149.

[28] G. L. Cui, W. Xu, C. W. Guo, X. W. Xiao, H. Xu, D. Q. Zhang, L. Jiang, D. B. Zhu, Journal of Physical Chemistry B 2004, 108, 13638-13642.

[29] B. Kirchner, Ionic liquids, Vol. 290, Springer, 2009.

[30] G. Gonfa, M. A. Bustam, Z. Man, M. I. Abdul Mutalib, Asian Trans. Engl 2011, 1, 24-34.

[31] G. Clavel, J. Larionova, Y. Guari, C. Guerin, Chemistry-a European Journal 2006, 12, 3798-3804

[32] K. Philippot, B. Chaudret, in Comprehensive Organometallic Chemistry III, Vol. 12, Applications III: Functional Materials, Environmental and Biological Applications (Eds.: R. H. Crabtree, M. P. Mingos), Elsevier, 2007, pp. 71-99.

[33] A. Angelova, A. Moradpour, P. Auban-Senzier, Synthetic Metals 2004, 143, 187-190.

[34] J. J. Storhoff, A. A. Lazarides, R. C. Mucic, C. A. Mirkin, R. L. Letsinger, G. C. Schatz, Journal of the American Chemical Society 2000, 122, 4640-4650.

[35] J. A. Becker, R. Schafer, R. Festag, W. Ruland, J. H. Wendorff, J. Pebler, S. A. Quaiser, W. Helbig, M. T. Reetz, Journal of Chemical Physics 1995, 103, 2520-2527.

[36] a) T. Hasegawa, J. Takeya, Science and Technology of Advanced Materials 2009, 10, 024314; b) T. Mori, in Molecular materials (Eds.: S. V. Malhotra, B. L. V. Prasad, J. Fraxedas), CRC Press, 2017, pp. 241270.

[37] I. Sarkar, M. Laux, J. Demokritova, A. Ruffing, S. Mathias, J. Wei, V. Solovyeva, M. Rudloff, S. S. Naghavi, C. Felser, M. Huth, M. Aeschlimann, Applied Physics Letters 2010, 97, 111906-111906.

[38] Y. Li, F. Jian, Journal of Materials Chemistry C 2014, 2, 1413-1417.

[39] S. Georgakopoulos, A. Pérez-Rodríguez, A. Campos, I. Temiño, S. Galindo, E. Barrena, C. Ocal, M. Mas-Torrent, Organic Electronics 2017, 48, 365-370.

[40] T. Hasegawa, M. Hiraoka, T. Yamada, Thin Solid Films 2010, 518, 3988-3991.

[41] a) T. Minari, M. Kano, T. Miyadera, S. D. Wang, Y. Aoyagi, M. Seto, T. Nemoto, S. Isoda, K. Tsukagoshi, Applied Physics Letters 2008, 92 173301; b) H. Wada, T. Mori, Applied Physics Letters 2008, 93 213303.
[42] a) T. Mori, Chemistry Letters 2011, 40, 428-434; b) K. Shibata, $\mathrm{H}$. Wada, K. Ishikawa, H. Takezoe, T. Mori, Appl. Phys. Lett. 2007, 90, 193509

[43] C. Han, Q. Sun, Z. Li, S. X. Dou, Advanced Energy Materials 2016, 6 1600498.

[44] B. Poudel, Q. Hao, Y. Ma, Y. Lan, A. Minnich, B. Yu, X. Yan, D. Wang, A. Muto, D. Vashaee, X. Chen, J. Liu, M. S. Dresselhaus, G. Chen, Z. Ren, Science 2008, 320, 634-638.

[45] C. Han, Z. Li, G. Q. Lu, S. Xue Dou, Nano Energy 2015, 15, 193-204

[46] O. Bubnova, X. Crispin, Energy \& Environmental Science 2012, 5, 9345-9362.

[47] a) Y. Sun, P. Sheng, C. Di, F. Jiao, W. Xu, D. Quu, D. Zhu, Advanced Materials 2012, 24, 932-937; b) R. Tkachov, L. Stepien, R. Grafe, O. Guskova, A. Kiriy, F. Simon, H. Reith, K. Nielsch, G. Schierning, D. Kasinathan, C. Leyens, Polymer Chemistry 2018, 9, 4543-4555.

[48] H. Itahara, M. Maesato, R. Asahi, H. Yamochi, G. Saito, Journal of Electronic Materials 2009, 38, 1171-1175.

[49] K. Bender, K. Dietz, H. Endres, H. W. Helberg, I. Hennig, H. J. Keller, H. W. Schäfer, D. Schweitzer, Molecular Crystals and Liquid Crystals 1984, 107, 45-53.

[50] a) K. Yuan, Z. Jiang, B. Jurado-Sánchez, A. Escarpa, Chemistry - A European Journal 2019, 26, 2309-2326; b) X. Chen, J.-H. Ahn, Journal of Materials Chemistry B 2020, 8, 1082-1092; c) M. A. Zoroddu, S. Medici, A. Ledda, V. M. Nurchi, J. I. Lachowicz, M. Peana, Current medicinal chemistry 2014, 21, 3837-3853; d) M. D. Mauricio, S Guerra-Ojeda, P. Marchio, S. L. Valles, M. Aldasoro, I. EscribanoLopez, J. R. Herance, M. Rocha, J. M. Vila, V. M. Victor, Oxidative Medicine and Cellular Longevity 2018, 2018, 20; e) P. Dubey, I. Matai, S. U. Kumar, A. Sachdev, B. Bhushan, P. Gopinath, Adv Colloid Interface Sci 2015, 221, 4-21; f) H. Bahadar, F. Maqbool, K. Niaz, M. Abdollahi, Iranian biomedical journal 2016, 20, 1-11.

[51] R. Pauliukaite, A. Malinauskas, G. Zhylyak, U. E. Spichiger-Keller, Electroanalysis 2007, 19, 2491-2498.

[52] J. Kulys, V. Simkeviciene, I. J. Higgins, Biosensors and Bioelectronics 1992, 7, 495-501. 


\section{WILEY-VCH}

\section{MINIREVIEW}

Mr. Kane Jacob is assistant engineer within the LCC "Molecules and Materials" team since 2004. He is a research support for this team and has notably contributed to the preparation of the first nanoparticles of Bechgaard salts, using electrochemical route in presence of ionic liquid. $\mathrm{He}$ is also the referent of the team for microscopy investigations.

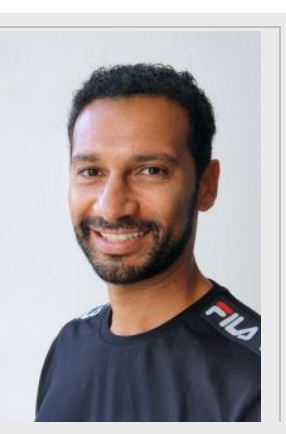

Prof. Dominique de Caro began working on the synthesis and optical properties of metal nanoparticles. His current research area concerns the preparation of thin films, nanowires and nanoparticles of moleculebased conductors and magnets. Since 2012 , he has been managing the LCC "Molecules and Materials" team.
Dr. Christophe Faulmann is Director of research at CNRS. He graduated from University of Toulouse-Paul Sabatier with major skills in XRD, magnetism and conductivity measurements and joined CNRS in 1990. He conducted various research projects towards multiproperty materials combining conductors, magnets and spin crosswover systems, and their

preparation as films and nanoparticles.

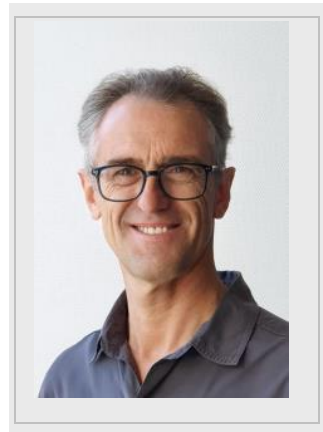

Dr. Lydie Valade is Director of research at CNRS. She graduated from University of Toulouse-Paul Sabatier and entered CNRS in 1983. She prepared the first superconductors based on the dmit metal complex family and studied processing techniques at RPI (Troy, NY). She led the LCC "Molecules and Materials" team from 2003 to 2011. Her research interests focus on the processing of molecular materials.
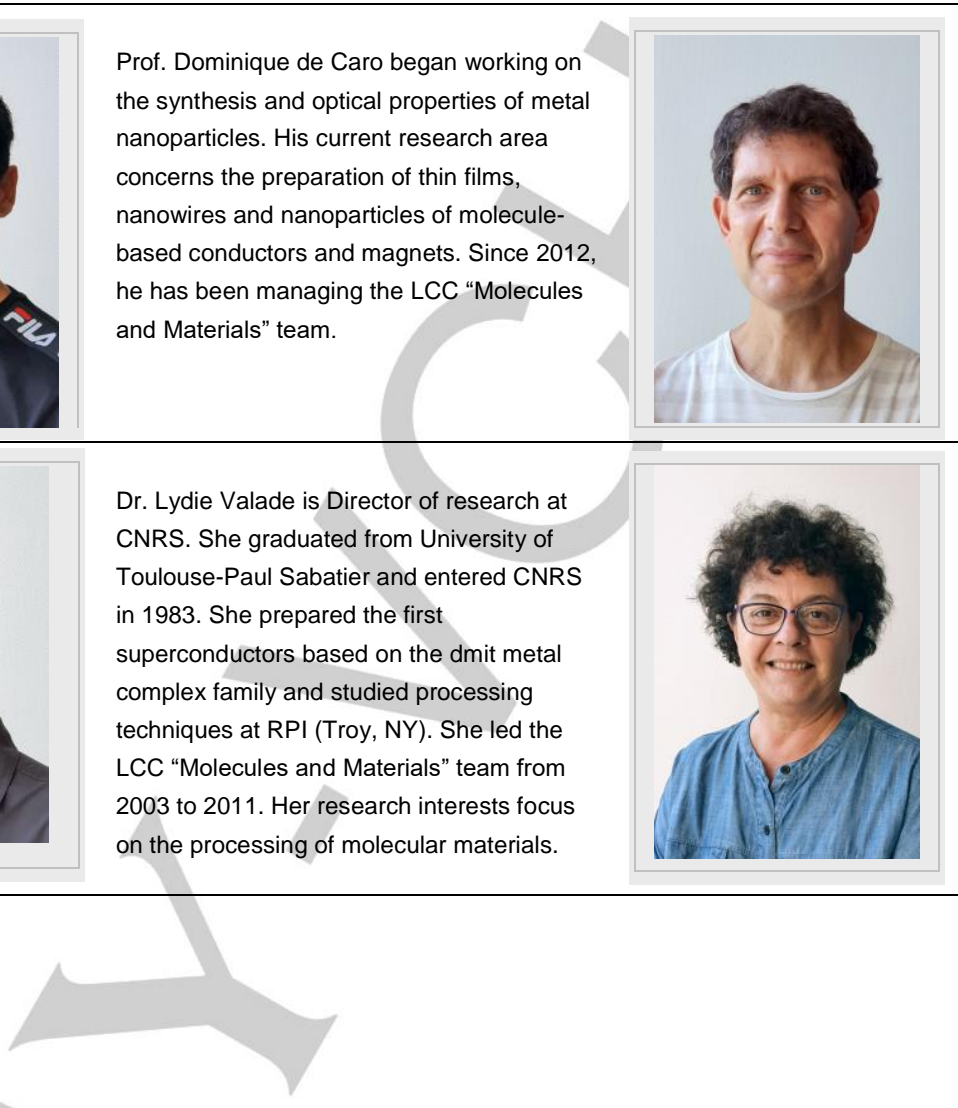

Table of Contents

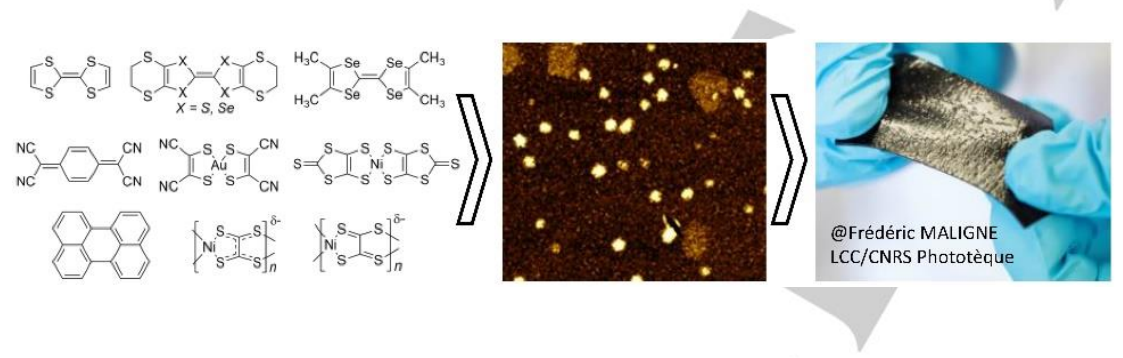

Towards integrable nanoscale molecular conductors and superconductors: conditions for growing nanoparticles of 1D molecular conductors and superconductors are reviewed for fourteen compounds and their chemical and physical properties at nanoscale are compared to bulk ones. Examples of their potential integration into composites, OFETs, thermoelectric materials and biomaterials are described.

\section{Key Topic}

Molecular nanoconductors

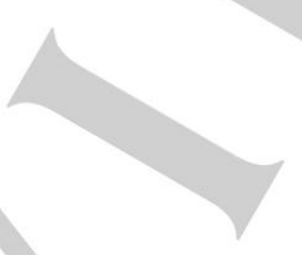

Twitter

Institute Twitter username: @LCC_CNRS 